shading about one third of the whole opening of the pupil from the retina behind. The outline of the tumor is a single curved line, and its surface apparently smooth and rounded.

Diagnosis.-Extravasation of blood under the choroid coat, or the uvea, or both.

Ticatment.-Absolute rest of the eye from close application, and avoidance of strong daylight and artificial light. Bathing around the orbit frequently with a tepid infusion of opium (gr. 10 to a teacupful of boiling water).

March 28th.-No pain, tenderness, nor redness of the globe. Vision improved. The tumor as before, but perhaps mounting not quite so high behind the iris. Ung. iodini daily to left temple.

May 26th.-Vision now as good as before the occurrence of the tumor, and since the cut with the stone-that is, very ncarly as good as with the sound cye. The tumor is now very sensibly diminished, rising, probably, when the iris is not under the influence of stramonium, not above the margin of the pupil, while its surface is no longer smooth, but corrugated, its superior outline being very irregular and uneven. This result $I$ conceive to be corroborative of the diagnosis.

At the second and third visits, the symptoms of inflammation or irritation having subsided, I examined the eye by the ophthalmoscope. Of the general complexion of the tumor, it gave a less satisfactory exhibition than ordinary daylight with a powerful lens, but it revealed one important fact, that the anterior portion only of the choroid in the immediate neighborhood of the ciliary system, was involved in it, and enabled me very early in the treatment to make a favorable prognosis as to the recovery of vision.

The loss of vision at first was probably duc not wholly to the interposition of the tumor between the retina and a portion of the pupil, but also to pressure of the tumor upon the lower side of the crystalline lens, displacing it enough to disturb the refrac. tion of light in its passage to the retina.

\title{
THREE CASES OF FUNIS PRESENTATION TREATED SUCCESSFULLY BY THE POSTURE METHOD.
}

By S. BRandeis, M.D., Louisville, KY.

Case I.-Mrs. Katharina Rehm, aged 30, a native of Germany, and who has borne four children (one of which was stillborn in consequence of prolapse of the funis), was seized with her fifth labor on the first day of July, 1858, at 4 o'clock, A.M. At 5 o'clock the membranes ruptured, followed by a full gush of liquor annii, which carried with it a long loop of the funis and the right hand. The midwife in attendance, having discovered the mischief, sent immediately for my assistance. 
I reached the patient within ten minutes, and found the funis, feebly pulsating, outside of the genitals, the hand within, and the head balloting high above the entrance of the pelvis. Remembering a plan suggested by Dr. Thomas, of New York, I forthwith placed the parturient on her knees and elbows, supporting the body with pillows in such a way that the pelvis was a good deal higher than the chest.

With slow and careful manipulations, I succeeded in placing both funis and arm far beyond the head, while I kept my hand within the cavity of the womb, in order to prevent a further prolapse. Strong labor pains set in, and, soon after, the head engaged so firmly in the superior entrance of the pelvis that all apprehension of a procidentia of the funis vanished. The patient was now placed on her back, labor proceeded rapidly, and three quarters of an hour later a living child (a boy) was born.

The patient did very well afterwards. The placenta was spontaneously expelled, there was very little after-pain, and recovery took place rapidly. The child is now eighteen months old, vigor. ous and healthy.

CASE II.-Mrs. Katherine Rapp, aged 36, a native of Germany, a stout and healthy woman, and the mother of four children, was taken with labor pains at 8 o'clock, P.M., October 12 th, 1859. Soon after the arrival of the midwife, the membranes ruptured, and a loop of the funis and hand presented. I was summoned to the case at 11 o'clock, P.M. On examination, I found the midwife's diagnosis correct; the hand was the left one; the loop of the funis, still pulsating, was about three inches long; whilst the head was high above the entrance of the pelvis. The method described in Case I. was immediately carried into operation. The reposition of the parts prolapsed was accomplished in about ten minutes. Labor pains were rather slow for about three quarters of an hour, and the patient, having been very much fatigued by her uncomfortable position, was permitted to lie on the left side with a high pillow under the hips. The pulsation of the child's heart, which had been very feeble, now recovered its full strength, labor-pains re-appeared, the head engaged firmly in the pelvis, no further prolapsus occurred, and, at half-past twelve, a loud-crying child (a boy, eleven pounds in weight) made its appearance. Childbed proceeded without the least disturbance. The child is now four months old.

CASE III.-Mrs. Elizabeth Bohn, aged 36, native of Germany, of vigorous frame, but somewhat reduced by a bronchial catarrh, which persisted during the later months of gestation, sent for a midwife at 11, P.M., February 3d, 1860 . The pains were so slow and feeble that patient and midwife slept several hours during. the night. At 5 o'clock, A.M., contractions of the womb re-appearing more forcibly, the membrane ruptured; after which the midwife 
discovered the funis projecting through the os uteri, but could not find any foetal part presenting. My assistance was called for at 7 o'clock, A.MI., February 4th, 1860.

On examination, I found the funis in from four to five small loops projecting through the os uteri, which was only partially dilated; the head being high above the pelvis, I could discover only by introducing my full hand.

After placing my patient in the position already described, efforts were made to replace the funis, which was more difficult in this case than in the two former, as several loops were projecting, and one would drop down while another was carried up; but nevertheless the aim was accomplished in a very short time, and the operating land kept within the uterus, in order to prevent another prolapsus. In the meantime, the uterine contractions propelled the head into the pelvis. The patient was now placed once more on her back (to her great comfort), and auscultation soon convinced me of the child's life.

Labor proceeded rapidly, and at quarter past 8, A.M., one hour after my arrival, a crying child proclaimed to me once more the success of the operation.

The patient had some after-pains, which yielded to slight medication. She is now doing well.

A few remarks on the merits of the operation employed in the cases just reported, will be permitted.

The presentation, or rather the prolapsus of the funis, is by all authorities in the art of accouchement considered as a complica. tion most disastrous to the life of the fœtus, and the great variety of contrivances invented for the occurrence is the most eloquent testimony for the difficulty of its removal.

The space granted to this paper does not permit the reporter, nor is it his aim, to go into a detail of the various modes of treatment; but it may be remarked, that not only the life of the fœtus, but the life as well as the health of the mother, is often endangered or lost through the severe operations-forceps, version and craniotomy-often resorted to, after repeated efforts have failed to replace the funis. The following table, collected from the highest authorities, shows the numerical proportion of this occurrence :

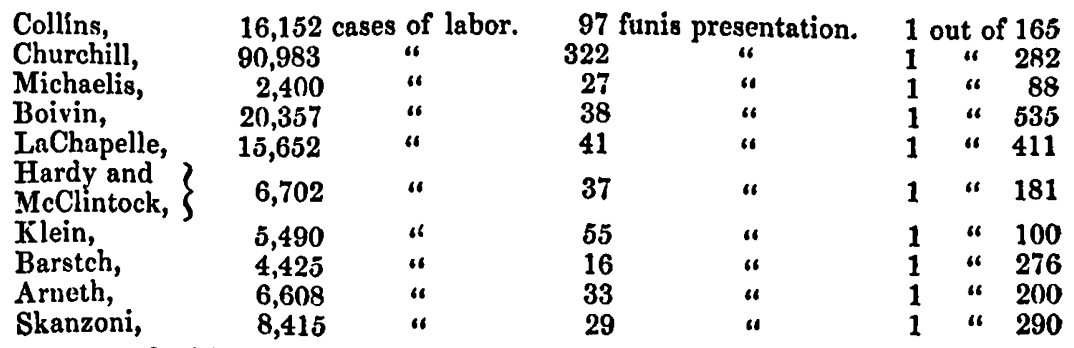

Out of 177,184 accouchements, which is the total amount of the 
figures just referred to, prolapsus of the funis occurred 695 times, giving a proportion of one $1: 264$, showing that this anomaly is one of the most frequent disturbances of labor.

Another table will show the relative mortality of children born under these circumstances:

$\begin{array}{lrr} & \text { Proldisus OF FUNIS. } & \text { CHILDREN } \\ \text { Mauriceau, } & 39 & 15 \\ \text { De La Motte, } & 14 & 5 \\ \text { Clarke, } & 66 & 49 \\ \text { Collins, } & 97 & 24 \\ \text { Churchill, } & 322 & 220 \\ \text { Hardy and McClintock, } & 37 & 25 \\ \text { La Chapelle, } & 41 & 8 \\ \text { Nichaelis, } & 27 & 20 \\ \text { Boirin, } & 38 & 18 \\ \text { Arneth, } & 33 & 11 \\ \text { Skanzoni, } & 29 & 13 \\ & 743 & 408\end{array}$

Thus, 743 cases of prolapsus funis gave 408 stillborn children, a proportion of $1: 1.82$, which shows clearly enough that accoucheurs have not been very successful in treating this kind of labor.

The rationale of the posture method being obvious to every skilful practitioner, we shall, in conclusion, try to give the indications for it.

First. The operation is only admissible as long as circulation exists in the funis; even if the circulation is feeble, it may soon be restored after the impediment is removed.

Second. The os uteri must be sufficiently dilated or dilatable.

Third. The liquor amnii must be partly retained; otherwise, if it should all have escaped, and the uterus be firmly contracted over the child's body, every effort for the reduction of the prolapsed funis would be in vain.-Louisville Medical Journal.

\section{A CASE OF ARGYRIA, WITH DEPOSIT OF SILVER IN THE INTES. TINES, LIVER, KIDNEYS, AND SPLEEN.}

By Dr. C. Fromanas.

THE subject of this paper, W. Jordan, aged 60, was attacked in March, 1856, with epilepsy, the fits occurring three to four times daily during the first month, when they lasted an hour at a time; they subsequently became less frequent, and at the end of the year they occurred once a fortnight, and only lasted about a quarter of an hour. Almost from the commencement of the disease, nitrate of silver was exhibited, and. for nine months he took a daily pill containing six grains, so that altogether he swallowed about $3 \frac{1}{2}$ ounces. Towards the end of July, the skin began to be discolored, gastritic symptoms supervened, but still the remedy was persevered with. - In the beginning of 1867 , there was ha. 